\title{
The ignition fragment wood heated to a high temperature of the plate.
}

\author{
Arkadiy V. Zakharevich a , Victor D. Velikanov and Eugene A. Vympin \\ National Research Tomsk Polytechnic University, 634050 Tomsk, Russia
}

\begin{abstract}
It is detected, that the main ignition regularities of dispersed wood possible on the basis of experimental studies in terms of the real modes of ignition. The aim of this article is the experimental study of the conditions and characteristics of the single ignition fragments wood the made of dry pine during heating energy intensive metal plate with a constant temperature. The experiments were carried out with particles of wood characteristic sizes. As a result the experimental studies were identified, typical ranges of sample sizes with maximum temperatures of ignition. The results of our experimental studies are the basis for selection of a specific optimization parameters (the temperature of the steel plate and the ignition delay time) when selecting a pulse pyrolysis technologies. Established in experiments regularities allow us to determine fireproof conditions of pyrolytic processes of wood processing in the mode heating pulse for the purpose of biofuel production.
\end{abstract}

\section{Introduction}

Forest biomass (wood) is considered to be a promising fuel for many regions of Southeast Asia, not only in private households, but also in industrial production [1-3]. Besides direct combustion on steam and hot water boilers of small or medium capacity, it is also possible the thermal conversion of wood to produce liquid motor fuels (pyrolysis liquids) [4], biogas [5] and biochar [6]. Thus are possible various conversion technologies (e.g., prolonged nizkotemperaturnogo or pulsed intensive heating) [6].

Development of technological modes the processing wood paired with a selection of the main ranges of operating parameters (size of single pieces of wood and heating temperatures). On the one hand comminution of feedstock (wood) simplifies its thermal conversion process, on the other hand, the high energy consumption dispersion on wood. Besides, it is known [7] that the dispersed wood is flammable. Therefore the choice of the size of single pieces of wood and the operating temperature [6] should be linked. In the present time there are no data on the conditions and characteristics of wood ignition fragments with characteristic dimensions (units of millimeters) by heating the wall surface pyrolytic reactor with temperature [6] up to $900 \mathrm{~K}$.

The general theory of thermal decomposition and ignition charred materials on the organic or polymer-based [8] can be used only when a known constants, characterizing the process of thermal decomposition and thermal properties of its products. The determination of these constants is not less difficult problem compared with the problem of ignition. Therefore, experimental determination of

${ }^{\text {a } C o r r e s p o n d i n g ~ a u t h o r: ~ b e t @ t p u . r u ~}$ 


\section{MATEC Web of Conferences}

conditions and the ignition characteristics of single fragments wood when interacting with the hot plate is the most appropriate. It should be noted that the results of the experimental [7-10] and theoretical [11-13] studies ignition solid [7,9,10] and liquid [11,14] condensed substances (CS) is set to a number of significant features of the ignition mechanisms when local heating arising from the specific heat exposure.

Singling out the general regularities of ignition, established in [7-14], we can conclude that the obtained results of experimental studies in inpatient intensive heating of the kinetic parameters of the process do not meet the conditions of local heating of a condensed substance by a source of limited capacity. Therefore, most likely, the induction period during local thermal impact is significantly different from the delay time of ignition under standard conditions [15]. The paper purpose is experimental study of the conditions and characteristics of the wood single pieces ignition in energyintensive heating of the metal plate with a constant temperature.

The paper purpose is experimental study of the conditions and characteristics of the wood single pieces ignition in energy-intensive heating of the metal plate with a constant temperature.

\section{Experimental research methodology}

The experimental technique of generally corresponded to that described in [7]. The fragments of crushed wood with a characteristic size of from 0.5 to $6 \mathrm{~mm}$ were dried in a drying oven for several hours. In the experiments they were dropped on a heated solid steel plate with a smooth and even surface (about $10 \mathrm{~cm}^{2}$ ). Temperature measurement was conducted by a chromel-alumel thermocouples at several points of the heating surface. Thermal conditions (heating rate) was chosen in such a way that by the time of contact with condensed substance (CS), the surface temperature of the heat source $\left(\mathrm{T}_{0}\right)$ reached a stationary regime. Each experimental condition was controlled strictly for repeating all experiments. The experiments series $(6-8)$ conducted at room temperature $298 \mathrm{~K}$ and relative humidity of $64 \%$ for each piece of wood at a constant value $\mathrm{T}_{0}$. The video filming of investigated process was occurred. Registered moments wood fragments contact with the heating surface and the appearance of the flame. The value of ignition delay time was determined after videograms' processing. The definition systematic errors of value $\tau_{i g n}$ were not more than $\pm 25 \%$ at low temperatures $T_{0}$. The error is significantly decreased with the increase of $T_{0}$.

\section{The discussion of experiments' results}

The experiments were done with particles of varying degrees of wood dispersion (typical dimensions: 1). $\mathrm{d}=0,5 \div 1 \mathrm{~mm} ; 2$ ). $\mathrm{h}=2 \times 2 \times 2 \mathrm{~mm} ; 3) . \mathrm{h}=2 \times 2 \times 4 \mathrm{~mm} ; 4) . \mathrm{h}=2 \times 2 \times 6 \mathrm{~mm}$ ). The research task were: determination of the limiting conditions of the ignition temperature of the heat source and the relationship $\tau_{\mathrm{ign}}=\mathrm{f}\left(\mathrm{T}_{0}\right)$. The main results of the experiments for samples of wood, made of dry pine, shown in Fig.1.

It is may be note, that with the increase of the characteristic samples size the significantly change the limit temperature of ignition (Fig.1). the minimum temperature of ignition makes $913 \mathrm{~T}_{0}$ for the fragments of wood a $2 \times 2 \times 2 \mathrm{~mm}$, while for a standard the reaction of burning begins sizes a $2 \times 2 \times 4 \mathrm{~mm}$ only at $\mathrm{T}_{0}>950 \mathrm{~K}$. Additionally, the delay time of ignition when identical $\mathrm{T}_{0}$ increases (Fig. 1) in the range of relatively low temperatures $\left(\mathrm{T}_{0}<1050 \mathrm{~K}\right)$ with the increasing size of the CS sample. With increasing temperature of heat source size impact specimens leveled - when $T_{0}>1100 \mathrm{~K}$ and $\mathrm{t}$ values are virtually identical. It should be noted that at large $T_{0}$ the errors of determination of $\tau_{\text {ign }}$ (do not exceed $\pm 5 \%$ ) go dropping considerably. The established regularities can be explained with the use of hypotheses and models formulated in [7-12] according to the results of the performed experiments.

On the videograms' you can clearly see the influence of several factors on the process realization corresponding to the ignition. So, it is established that at any height of a wood sample in a parallelepiped-shaped full ignition occurs at the bottom of charring 2-4 $\mathrm{mm}$ from the heating surface. 


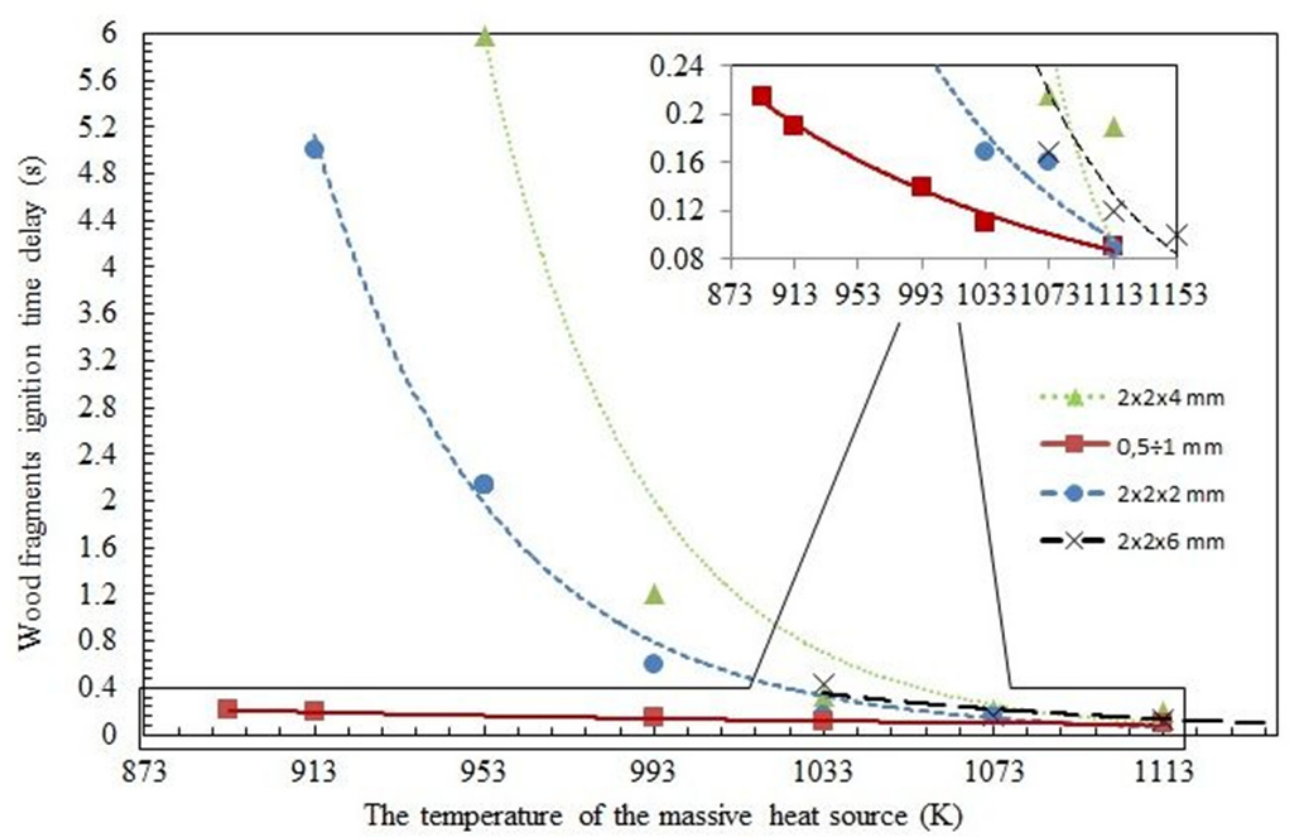

Figure 1. Experimental dependences of the dispersed wood ignition delay time of from massive initial temperature of the heat source.

This area of the reaction ignition is thin near-wall region above the upper edge of the sample, if $h<4$ mm (Fig. 2). The ignition occurs in areas adjacent to a lateral edge (Fig. 3) the layer of a mixture of air and heated to elevated temperatures the products of thermal decomposition, if $h>4 \mathrm{~mm}$. Ignition of the fuel mixture (the gaseous products of thermal wood decomposition) and oxidant (air) occurs after its preheating while moving along the lateral edge of the parallelepiped-shaped, it can be assumed by analogy with [12-14]. The wood is not heated to high temperatures in large parts of the lateral edge area of the sample in the initial period of time. After charring, and a corresponding increase in the temperature, the lateral edges become suppliers of gaseous fuel and a source of heating the reactive mixture. The additional influx of energy and fuel provides the conditions of gas-phase ignition of wood at by the increase of time.

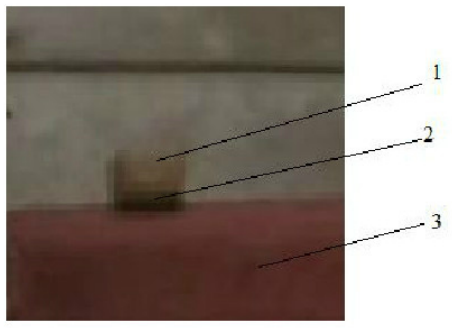

a)

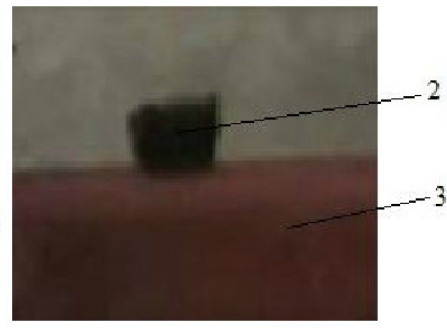

b)

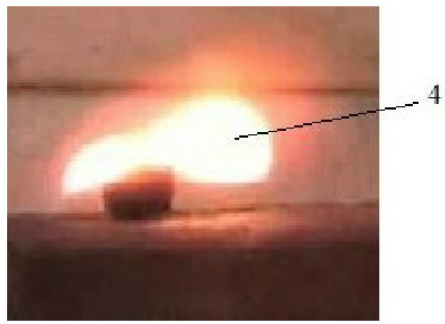

c)

Figure 2. Typical pictures with an image of the igniting process dispersed wood $(2 \times 2 \times 2 \mathrm{~mm})$.

a) $\tau_{\text {ign }}=0,6 \mathrm{sec}-$ the beginning process of wood thermal decomposition of the lower part; b) $\tau_{\text {ign }}=3,12 \mathrm{sec}-$ charring of wood fragment; c) $\tau_{\text {ign }}=4,92 \mathrm{sec}-$ gas-phase ignition of wood above the top border. $1-$ wood; $2-$ charring of the wood fragment; 3 - massive heat source; 4 -flame on the top face of the wood.

It can be noted that in conditions of relatively low temperature heat source - plate (Fig. 1) the gasification products do not have time to warm up to the sufficient ignition temperature of the 


\section{MATEC Web of Conferences}

combustible mixture. In addition the decline of $\mathrm{T}_{0}$ leads and to falling of speed of gasification. As a result the concentration of combustible components goes down in the zone of heating.

The analysis of obtained results allows to conclude that high-temperature pulsed pyrolysis technology [4] it is possible by heating the surface of the reactor to a temperature of $\approx 800 \div 850 \mathrm{~K}$, characteristic even at small samples sizes of forest biomass $(1 \div 2 \mathrm{~mm})$. With such restrictions on t0 pyrolytic process, as shown by the experiments, occurs without ignition until the complete charring of the starting material in an oxidizing environment, while ensuring certain conditions of heat removal from the zone of wood thermal decomposition for periods of time $5 \div 10$ seconds from the start of heating.

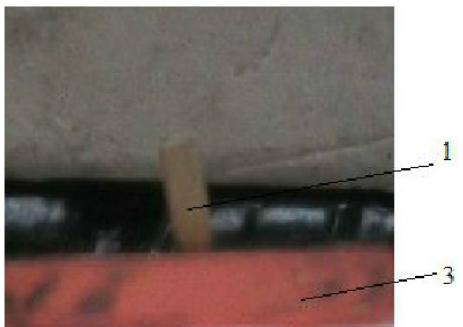

a)

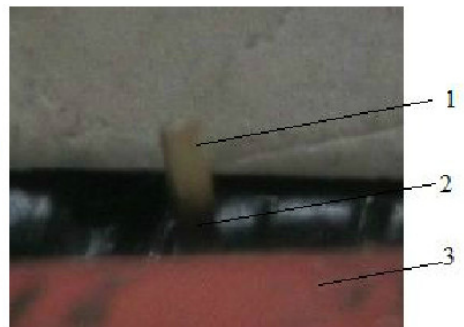

b)

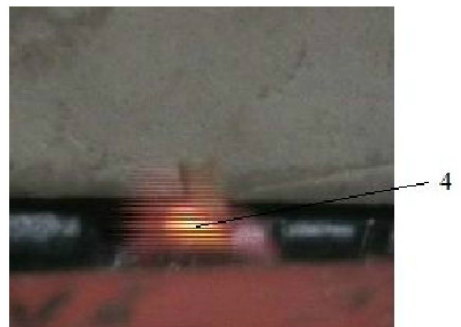

c)

Figure 3. Typical pictures with an image of the igniting process dispersed wood ( $2 \times 2 \times 6 \mathrm{~mm})$.

a) $\tau_{\mathrm{ign}}=0,12 \mathrm{sec}-$ the beginning process of wood thermal decomposition of the lower part; b) $\tau_{\mathrm{ign}}=0,36 \mathrm{sec}-$ charring of wood fragment; c) $\tau_{\text {ign }}=0,44 \mathrm{sec}$ - gas-phase ignition of wood at the side. 1 - wood; 2 - charring of the wood fragment; 3 - massive heat source; 4 -flame on the top face of the wood.

At the same time, experiments have shown that when choosing a pulse pyrolysis technologies have the ability to optimize certain parameters by selecting the dimensions of the sample. According $\tau_{\text {ign }}$ $\left(\mathrm{T}_{0}\right)$ are shown (Fig. 1) that when the characteristic size of the samples more than $2 \mathrm{~mm}$ (which is quite acceptable in the preparation of raw materials for subsequent thermal conversion) ignition of wood at the temperature of the heating surface $\mathrm{T}_{0}$ less than $900 \mathrm{~K}$ does not occur even at the time more than $5 \mathrm{sec}$. Therefore, the most preferred are fragments of wood with a characteristic size of $2 \div 4$ $\mathrm{mm}$ from the viewpoint of minimizing the cost to the dispersion and fire safety of the process.

Based on the analysis of the experimental results it can be concluded that heat transfer to the surface CS plays a dominant role in regulating the delay time of ignition. The kinetics of the process, of course, does not change with the increasing size of the wood fragments. Changing the values of the ignition delay time and size of condensed matter differ only by modifying the heating conditions mixture of gaseous products thermal decomposition of wood and air, moving along the lateral edges of the specimen.

\section{Conclusions}

The experimental results are the basis for the updating of wood models ignition in conditions of local heating. The identified effect of sample size on the ignition delay time illustrates the dominant influence of heat transfer on the sufficient formation conditions for the combustion process (the temperature of the fuel mixture and oxidant, and also the concentration of fuel). The established regularities also illustrate the possibility flame-proof conditions choosing pyrolytic processes of wood processing in the mode pulsed heating intense for the purpose of producing biogas, biochar and liquid fuel. The technology of pulsed pyrolysis, as shown by the experiments, have great potential for development. 


\section{References}

1. G.V. Kuznetsov , R. N. Kulesh, M. Polsongkram, Izvestiya Tomskogo politehnicheskogo universiteta 320, 22 (2012)

2. E.A. Bramer, M.R. Holthuis, G. Brem, Proc. of the Second World Biomass Conference, 963 (2004)

3. G.V. Kuznetsov, M. Polsongkram, XVI international conference modern technique and technology, 198 (2010)

4. T.A. Zheleznaya, G.G. Geletuha, Promyishlennaya teplotehnika 27, 91 (2005)

5. A. Zabaniotou, O. Ioannidou, E. Antonakou and A. Lappas, Int. J. hydro. Eng 33, 2433 (2008)

6. J. Gaunt, J. Lehmann, J. Environ. Sci. Technol 33, 4152 (2008)

7. A.V. Zakharevich, Journal of Engineering Physics and Thermophysics 87, 98 (2014)

8. V. L. Strakhov, A. N. Garashchenko, G. V. Kuznetsov and V. P. Rudzinskii, Combustion, Explosion, and Shock Waves 37, 178 (2001)

9. A. V. Zakharevich, G. V. Kuznetsov, V. I. Maksimov and V. T. Kuznetsov, Combustion, Explosion, and Shock Waves 44, 543 (2008)

10. D.O. Glushkov, G.V. Kuznetsov, P.A. Strizhak, Russian Journal of Physical Chemistry B 5, 1000 (2011)

11. O.V. Vysokomornaya, G.V. Kuznetsov, P.A. Strizhak, Russian Journal of Physical Chemistry B 5, $668(2011)$

12. G.V. Kuznetsov, G. Ya. Mamontov, G. V. Taratushkina, Khimicheskaya Fizika 23, 67 (2004)

13. G.V. Kuznetsov, G. Ya. Mamontov, G. V. Taratushkina, Combustion, Explosion and Shock Waves 40, 70 (2004)

14. G.V. Kuznetsov, P.A. Strizhak, J. Eng.Thermophysics 17, 224 (2008)

15. D.A. Frank-Kamenetsky, Diffusion and Heat Transfer in Chemical Kinetics ( Moscow Science, 1987) 